\title{
Climatic analysis linked to land vegetation cover of Mexico by applying multivariate statistical and clustering analysis
}

\author{
Luis F. PINEDA-MARTÍNEZ ${ }^{1 *}$ and Noel CARBAJAL ${ }^{2}$ \\ ${ }^{1}$ Unidad Académica de Ciencias de la Tierra-PEIDA, Universidad Autónoma de Zacatecas, Calzada Universidad 108, \\ 98058 Zacatecas, Zacatecas, México \\ ${ }^{2}$ Instituto Potosino de Investigación Científica y Tecnológica, A. C., San Luis Potosí, San Luis Potosí, México \\ *Corresponding author: email: lpineda@uaz.edu.mx
}

Received: April 7, 2016; accepted: May 24, 2017

\begin{abstract}
RESUMEN
Se delimitan las regiones climáticas de México mediante el análisis jerárquico de agrupamiento. Los datos utilizados fueron medias mensuales de temperatura máxima y mínima y la precipitación mensual acumulada, obtenidas de estaciones climáticas en México para el periodo 1961-2004. Este método de agrupamiento asigna cada variable de precipitación y temperatura a grupos con base en características estadísticas similares. Se realizó un análisis de componentes principales para obtener una matriz estandarizada que se utilizó en el agrupamiento. Aplicando dos criterios de agrupamiento (K-means y Ward) fue posible definir estadísticamente los grupos de estaciones que delimitan regiones de clima similar. Además, la metodología empleada describe la distribución de la vegetación dominante para cada región climática. Este análisis puede contribuir a la generación de nuevos escenarios climáticos, donde puede incluirse la dinámica de la cobertura vegetal como bioindicador del clima.
\end{abstract}

\begin{abstract}
The climate regions of Mexico are delimitated using hierarchical clustering analysis (HCA). The data used consists of monthly means of maximum and minimum temperatures and monthly-accumulated precipitation. The dataset was obtained from heterogeneously distributed climatic stations in Mexico for the period from 1961 to 2004. This cluster method assigns precipitation and temperature variables to groups of clusters based on similar statistical characteristics. We carried out a principal components analysis to obtain a standardized reduced matrix to be used in HCA. By applying two clustering criteria (K-means and Ward's method) it was possible to define statistically groups of stations that delimit regions of similar climate. In addition, the applied methodology describes the dominant vegetation distribution for each climate region. This analysis may contribute to the generation of new climate scenarios, where the dynamics of land vegetation cover could be included as a biomarker of climate.
\end{abstract}

Keywords: Hierarchical clustering analysis, principal component analysis, climate of Mexico, vegetation distribution. 


\section{Introduction}

The relationship between climate and vegetation distribution has been used to make inferences about changes in the behavior patterns of both components. The classification of climatic regions can contribute to the knowledge about climate change and the potential distribution of vegetation (Bonan et al., 2003). There has been a climate typing attempt to introduce a series of rules in order to generate climatic regionalization based on the statistical analysis of long-term meteorological data. One of these statistical analyses, based on eigen techniques, represents an alternative that can be used to generate reproducible climatic maps (Richman, 1981). The climatology of Mexico has been described by some authors (García, 2004; Comrie and Glenn, 1998; Englehart and Douglas, 2002; Giddings et al., 2005, Bravo et al., 2012). However, for new methodologies to be introduced, it is indispensable to understand climatic zoning based on statistical data analysis. When defining climate regions, typically, long-term monthly means are employed from a set of climatic observations (temperature and precipitation) regarding a number of climatic stations (Pineda-Martínez et al., 2007). The principal aim of this research is to apply a hierarchical clustering analysis to historical meteorological data of Mexico.

Another aspect is the connection between climate and vegetation. The distribution of potential global vegetation is entirely related to the climate and geographical conditions (Neilson, 1995; Bonan et al., 2003). The estimation of vegetation distribution in terms of climatic regions can be a useful tool for future approaches not only for the climate but also for the redistribution of potential vegetation under climate change scenarios. These interactions are key for understanding the water balance and its impact on the hydrological cycle (Farmer et al., 2003).

The regions of native vegetation are adapted to contemporary climate conditions. As the climate changes every type of vegetation must change as well. The sites where climate becomes a factor of stress can cause changes in vegetation patterns and promote the invasion of exotic species (Cramer and Leemans, 1993). This kind of alteration of the vegetation cover may modify significantly the soil properties. The relationship between vegetation and climate is essential to understand the interactions between the ability of the soil to store water and its impact on the processes of potential evaporation and precipitation.

This work aims to define climate regions for the whole territory of Mexico based on hierarchical clustering analysis from 2324 selected climatic stations. Cluster analysis is a useful tool to define groups of objects within a dataset based on similarity, thus it allows to define climatic regions. Also, we generate a classification of the main types of vegetation in each climatic region. The database of vegetation types used for this study corresponds to the national forest inventory of 2000 (Palacio-Prieto et al., 2000). Vegetation types are grouped by dominant vegetation type in representative groups (Miranda and Xolocotzi, 1963).

In this paper we generate a climatic regionalization based on a robust statistical analysis. In the regionalization of climate we use vegetation cover as a guide to the discussion of the results. In this way, we focus on describing the main relationships between our climatic regionalization and vegetation patterns, and the topographic influence.

\section{Data and methodology \\ 2.1 Climate data}

We use 2324 stations across Mexico's territory $\left(14^{\circ} \mathrm{N}, 86^{\circ} \mathrm{W}\right.$ to $\left.33^{\circ} \mathrm{N}, 118^{\circ} \mathrm{W}\right)$ for which the date record spans 40 years. The data was obtained from the Comisión Nacional del Agua (Mexican water commission), and it includes observations from stations throughout Mexico (Fig. 1) (http://clicom-mex. cicese.mx).

For this research work, we consider monthly means of temperature maxima (January $=\mathrm{T} 1$ to December $=\mathrm{T} 12)$, monthly means of temperature minima $($ January $=\mathrm{t} 1$ to December $=\mathrm{t} 12)$ and monthly means of accumulated precipitation $(\mathrm{P})$ (36 variables in total), for a period from 1961 to 2004. In order to obtain a matrix of average values, we included stations with continuous information during the considered period and those with no more than $2 \%$ missing data. Precipitation and temperature values were evaluated using quality controls similar to Zhu and Lettenmaier (2007). The variables were standardized to a 0 mean and a standard deviation of 1 . No methods were applied to fill missing data. 


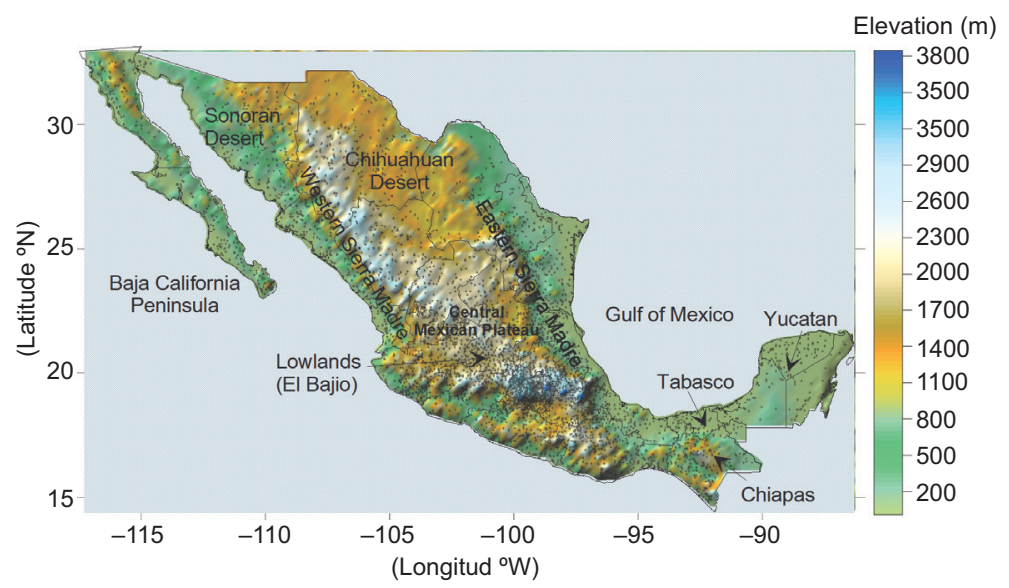

Fig. 1. Elevation map of Mexico including its main topography features. The most representative climate regions are indicated. The points represent the position of the considered stations.

\subsection{Principal components}

The PCA was implemented as described in Gong and Richman (1995). The data matrix was used to compute the covariance between all variables or entities $(A)$. The data matrix $X$ contains $n$ stations and $m$ variables $(2324 \times 36)$. The $n \times m$ data matrix yielded a $m \times m$ matrix. Since data were standardized the resulting product matrix of the anomalies would be a standardized anomaly matrix, also known as a correlation matrix. As mentioned by Estrada et al. (2009), a correlation matrix is used to avoid that variables with larger magnitudes would dominate in the PCA results. The matrix was diagonalized into a $m \times m$ matrix of eigenvalues and a matrix of eigenvectors. The eigenvectors were scaled by the square root of the corresponding eigenvalue. Once this was accomplished, some assessment of dimensionality is often applied to reduce the $m$ new variables (the principal components) to a smaller set, $r$ (Gong and Richman, 1995). For this research, we retained the principal component with eigenvalue $>1$.

The $m \times r$ matrix was transformed by a varimax orthogonal rotation to obtain an $m \times r$ matrix of rotated principal component loadings. From these rotated loadings, an $n \times r$ set of principal component scores are formed and a Euclidian distance measure is applied to those scores. The distances are used as inputs for the cluster analysis.

This PCA has the goal of replacing the correlated climatic original variables with new components, which are mutually uncorrelated based on the principle that each component is defined by an orthogonal basis (Richman, 1981). Thus, the eigenvector matrix resulting from this type of PCA is often truncated. retaining PC with eigenvalues $\geq 1$ (Gong and Richman, 1995).

The entries of this matrix, the eigenvectors or loadings, define new variables, consisting of linear transformations of the original variables. Thus, PCA generates another matrix that represents new uncorrelated variables (Richman, 1981).

\subsection{Cluster analysis}

Hierarchical cluster analysis (HCA) allocates a set of objects into groups or clusters on the basis of some measurement of similarity. This similarity or distance is an Euclidean measurement, i.e., it is a simple difference between two objects (Fovell and Fovell, 1993; Karlsen and Elvebakk, 2003).

Agglomerative cluster is an algorithm that starts with $n$ clusters, each containing one single object, and then neighbor cluster pairs merge iteratively at each step to create new clusters (Elmore and Richman, 2001). Thus, the number of remaining clusters is reduced by one after every step and the procedure finishes when only one cluster containing all the objects is created (Karlsen and Elvebakk, 2003).

In order to identify the minimum number of suitable clusters, a K-means clustering was carried out to group the data based on similarity of PC's. The 
$\mathrm{K}$-means algorithm is a convergent method where $k$ seed points are specified as a set of centroids of $k$ clusters. The Euclidean distance is computed; then each entity is assigned to a cluster having the nearest centroid to attain an initial partition. The minimum cluster number is determined under a convergent criterion by comparing the distances to all the $k$ clusters centroids.

Once a maximum number of clusters were obtained, we carried out an agglomerative hierarchical clustering using Ward's method, which is an agglomerative hierarchical cluster method that merges cluster pairs with the smallest inter-cluster Euclidean distance. Ward's method, the most frequently used for climatic classification (Kalkstein et al., 1987), utilizes inter-cluster minimum variance as the distance criterion for merging cluster pairs that show the minimum squared distance between centroids (Fovell and Fovell, 1993; De Gaetano, 1996). Ward's algorithm was carried out for the retained components from the PCA to obtain a climatic regionalization (Kalkstein et al., 1987). Since our final goal is the delimitation of climatic regions, every cluster will be classified using the Köppen climate classification modified by García (2004).

\subsection{Silhouette coefficient}

In order to determine the minimum cluster, the silhouette coefficient (SC) was computed. The method of silhouette coefficients combines both cohesion and separation (Tan et al., 2005).

In order to compute the silhouette coefficient for an individual point, a process that consists of the following three steps is carried out: 1) for the $i$ th object, its average distance to all other objects in its cluster $a i$ ' is calculated; 2) for the $i$ th object and any cluster not containing the object, the average distance to all the objects in the given cluster is calculated; the minimum value with respect to all clusters is $b i$; and 3 ) for the $i$ th object, the silhouette coefficient is $S i=(b i-U i) / \max \left(a i{ }^{\prime} b i\right)$ '.

The value of the silhouette coefficient can vary between -1 and 1 . A negative value is undesirable because it corresponds to a case in which $U i$, the average distance to points in the cluster, is greater than $b i$, the minimum average distance to points in another cluster. We want the silhouette coefficient to be positive ( $a i<$ $b i$ ), and for $a i$ to be as close to 0 as possible, since the coefficient assumes its maximum value of 1 when $U i=$ 0 . We can compute the average silhouette coefficient of a cluster by simply taking the average of the silhouette coefficients of points belonging to the cluster.

\section{Results and discussion}

\subsection{Principal component analysis}

Figure 2 shows PC loadings for the three first components; it is possible to observe that all variables are grouped on different sectors. PCA results show a distribution of temperatures associated to the first principal component (PC1) and precipitation variables associated to the second component (PC2). PC loadings are characterized by temperature variables through the PC1 with an explained variance of $52.9 \%$ and by precipitation variables through the PC2 with an explained variance of $19.2 \%$. The first three principal components amounted to $82.1 \%$ of the total explained variance. Additional components had a lower effect on variance explanation (eigenvalue $<1$ ).

As shown in Figure 2, monthly means of minimum temperature had the highest contribution to $\mathrm{PC} 1$, revealing the large variability of this parameter.

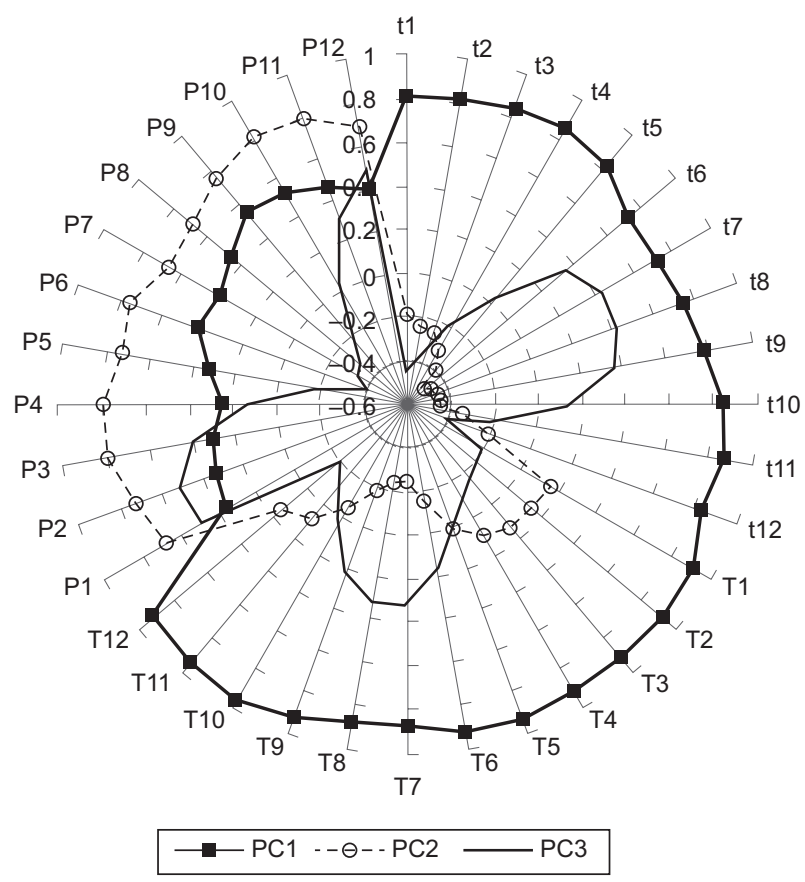

Fig. 2. Plot of principal components scores $\mathrm{PC} 1, \mathrm{PC} 2$, and PC3 for the 1961-2004 dataset. Precipitation (P) variables are represented in PC2 while PC1 is totally explained by maximum $(\mathrm{T})$ and minimum $(\mathrm{t})$ temperatures, respectively. PC3 represents seasonal variability. 
For instance, from an average temperature of $24^{\circ} \mathrm{C}$ in warmer climates (state of Tabasco) to $-4.25^{\circ} \mathrm{C}$ in colder ones (in the western Sierra Madre of Chihuahua, see Fig. 1). It is reflected in major correlation values for these variables (from November to March). Maximum temperatures are associated with negative loadings in PC2 except from January to March. Less variability in temperature is observed through all data for spring and summer months. In contrast, PC3 shows an influence of summer temperatures and for precipitation in winter months.

\subsection{Cluster analysis}

In order to generate the climate classification, it is necessary to delineate groups of stations which share similar meteorological characteristics. This delimitation was carried out by applying Ward's agglomerative hierarchical clustering to the three first retained principal components. The spatial interpolation was done using a geostatistical ordinary kriging method and an exponential variogram in order to represent each cluster in its geographical context. Krigging was used to interpolate the position of the stations in the climatic groups. We used the cluster number assigned to each station after clustering. Once the interpolation was carried out, the climatic classification was performed for each cluster. Based on the results of the $\mathrm{SC}$ we examined the 12-level clustering solution (Table I).
The average silhouette coefficient is always positive for all clusters, though some values are relatively low (close to 0 ) for specific groups of stations that present exceptional rainy climates (cluster 9). For these stations, grouped into clusters with larger SC values, the ranges of precipitation and temperature are low.

\subsection{Climate regions classification}

Clusters 4 and 5 reflect the semiarid climate regions (BSh and BSk) from the central part of Mexico northwards (Chihuahuan Desert). These climates present low seasonal precipitation during summer due to a subtropical high-pressure zone and as a result of the geographical barriers of the main mountain ranges of Mexico. The difference between these two climates is the maximum temperature for the warm months (from May to July). Other arid zones that include the Sonoran Desert and the Baja California Peninsula were grouped in clusters 7 and 8 (BS0 and BS1). Despite their statistical similitude in terms of temperature values, cluster 7 clearly defined areas within the region delimited by cluster 8 with a difference in total precipitation and low precipitation/temperature $(\mathrm{P} / \mathrm{T})$ ratio.

The transition between the southernmost part of the highlands (2000 masl) and the area in which the western and eastern Sierra Madre converge in the central highland are defined in clusters 1, 2 and 9.

Table I. Characteristics of the clusters produced by clustering analysis.

\begin{tabular}{lcccccl}
\hline $\begin{array}{l}\text { Cluster } \\
\text { ID }\end{array}$ & $\begin{array}{c}\text { Maximum } \\
\text { temperature } \\
\left({ }^{\circ} \mathrm{C}\right)\end{array}$ & $\begin{array}{c}\text { Minimum } \\
\text { temperature } \\
\left({ }^{\circ} \mathrm{C}\right)\end{array}$ & $\begin{array}{c}\text { Silhouette } \\
\text { coefficient }\end{array}$ & $\begin{array}{c}\text { Annual accumulated } \\
\text { precipitation } \\
(\mathrm{mm})\end{array}$ & $\mathrm{P} / \mathrm{T}^{*}$ & $\begin{array}{c}\text { Climate } \\
\text { classification }\end{array}$ \\
\hline 1 & 26.33 & 10.37 & 0.314 & 790 & 43.07 & Aw1hb3gx \\
2 & 31.24 & 19.06 & 0.390 & 1192 & 47.40 & Aw1hgx \\
3 & 20.77 & 6.04 & 0.456 & 952 & 70.99 & Cw2k'b3gx \\
4 & 31.29 & 15.89 & 0.187 & 524 & 22.21 & Bs0hb3x \\
5 & 24.75 & 8.13 & 0.177 & 563 & 34.26 & Bs1kb3n'x \\
6 & 33.08 & 18.79 & 0.227 & 1067 & 41.14 & Aw1hb3gx \\
7 & 29.31 & 12.24 & 0.384 & 266 & 12.79 & Bs0h \\
8 & 28.88 & 12.71 & 0.187 & 734 & 35.30 & Bs1h \\
9 & 30.28 & 19.34 & 0.050 & 2104 & 84.82 & Aw2hb3gx \\
10 & 25.74 & 9.18 & 0.178 & 372 & 21.30 & Bs0kb3n'x \\
11 & 23.34 & 12.02 & 0.324 & 1428 & 80.79 & Cfkb3gx \\
12 & 28.67 & 18.52 & 0.244 & 3654 & 154.85 & Aw2hx \\
\hline
\end{tabular}

$* \mathrm{P} / \mathrm{T}=$ mean annual precipitation/mean annual temperature. 
Cluster 9 (AW2) delimited the transition between temperate and humid climates near the Western Sierra Madre. The wetter climate regions in the southeastern part of Mexico were grouped in clusters 3 and 11 (Cwmh and $\mathrm{Cfh}$ ) defining the humid and temperate climate regions. These regions are located in the coastal plains, in the Yucatán Peninsula and in the highlands of Chiapas. Cluster 11 (Cfh) delineated all of the central mountain formations from the western Sierra Madre to the lowlands (E1 Bajío) in the central part of Mexico. Overall, the Yucatán Peninsula and regions in the coastal zone of the Gulf of Mexico are contained in cluster 2 (Aw1), which thus defined the rainy climates. Cluster 1 (AW1b3) is located in the regions of tropical rainy forests with a seasonal precipitation regime and temperate climate. The rainiest climate regions are delimited by clusters 11 (Cfk) in Tabasco and the southeast of Chiapas, where usually tropical cyclones impact (García, 2004).

The $\mathrm{P} /$ T relation gives us an idea of the similitude between stations or groups. For instance, clusters 9 and 12 represent the same climate classification but under a different $\mathrm{P} / \mathrm{T}$ regime. Thus, while cluster 9 has a $\mathrm{P} / \mathrm{T}$ ratio of 84.82 , for cluster 10 the ratio is 154.85. This means that large precipitations are most influenced by events such as tropical cyclones.

There are some implications for climate regionalization under global climate changes. Obviously, the present climates distribution will suffer changes for specific variables. In arid and semiarid regions in Mexico, the diurnal temperature oscillation has changed, mainly in its lower limits (Brito-Castillo et al., 2010). There is also a negative trend in soil moisture content from mid-latitude zones to the north-central region of Mexico, mainly due to low precipitation. This indicates a negative change in effective daily precipitation above $1 \mathrm{~mm}$ (Seager et al., 2007). These features needs to be considered in futures works on regional and local climate research.

\subsection{Vegetation and climatic regions}

Climate and topography control the distribution of many plants (Kelly and Goulden, 2008). Different species of plants have suffered some effects due to changes in temperature, especially during daytime. This has caused a variation in the species composition in latitudinal and altitudinal gradients (Chen et al., 2011). Another important factor is the variation of drought periods that can affect the composition of species through the seed establishment of new individuals. In addition, areas of native vegetation have been modified and disturbed by the direct action of human activities. The intensification of these activities has impacted simultaneously with the changing climate conditions at a regional scale. In many cases, the vegetation groups include, at least partially, communities that cannot be categorized as climax, but its existence is largely linked to the characteristics of the substrate (Miranda and Xolocotzi, 1963; Chapin et al., 2011). The present knowledge about land vegetation cover in Mexico does not allow comparative assessments in sufficient detail, except for specific sites and at a small scale (Rzedowski, 2006). Studies on vegetation are mainly focused on major vegetation types and they only show vegetation types as the basic unit of work. From the dynamic point of view, all vegetation types are described as stable biotic communities or plants based on the factors of the physical environment in which they live. For instance, although there are forests classified as secondary (mainly pine), others are the original plant or a mixture of both. Thus, vegetation types are grouped by dominant vegetation type in representative groups (Miranda and Xolocotzi, 1963). However, in this research work, we can infer reconstructions of the original vegetation. It is also possible to observe a relationship between the recent dominant vegetation and climate classification. This can be seen in Figure 3 .

Figure 4a shows the climate regionalization by using the Ward algorithms of HCA outputs. In Figure $4 \mathrm{~b}$ the climatology of García (2004) is included. In the climate maps of García, more detail is included regarding the types and subtypes of climates. In the climate regionalization of this study only the main climatic types of Mexico are considered, as it is observed in Figure 4c. The foremost similarities are shown for the main zones of the principal climatic groups, Aw1, Aw2, B1, B0, Cf and C. These are generally distributed in the same regions as those proposed by García (2004). The main differences are observed in the boundaries of each type of climate, since the allocation of climate regionalization is based on totally different methodologies and philos- 


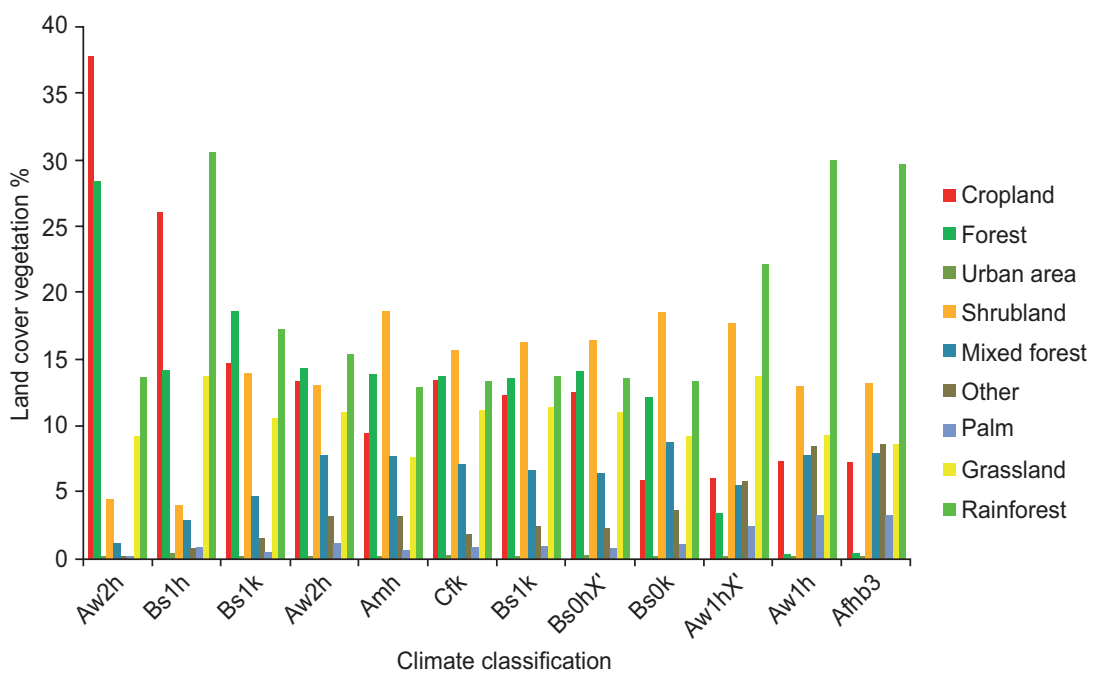

Fig. 3. Partial distributions of vegetation groups for climate type classification.
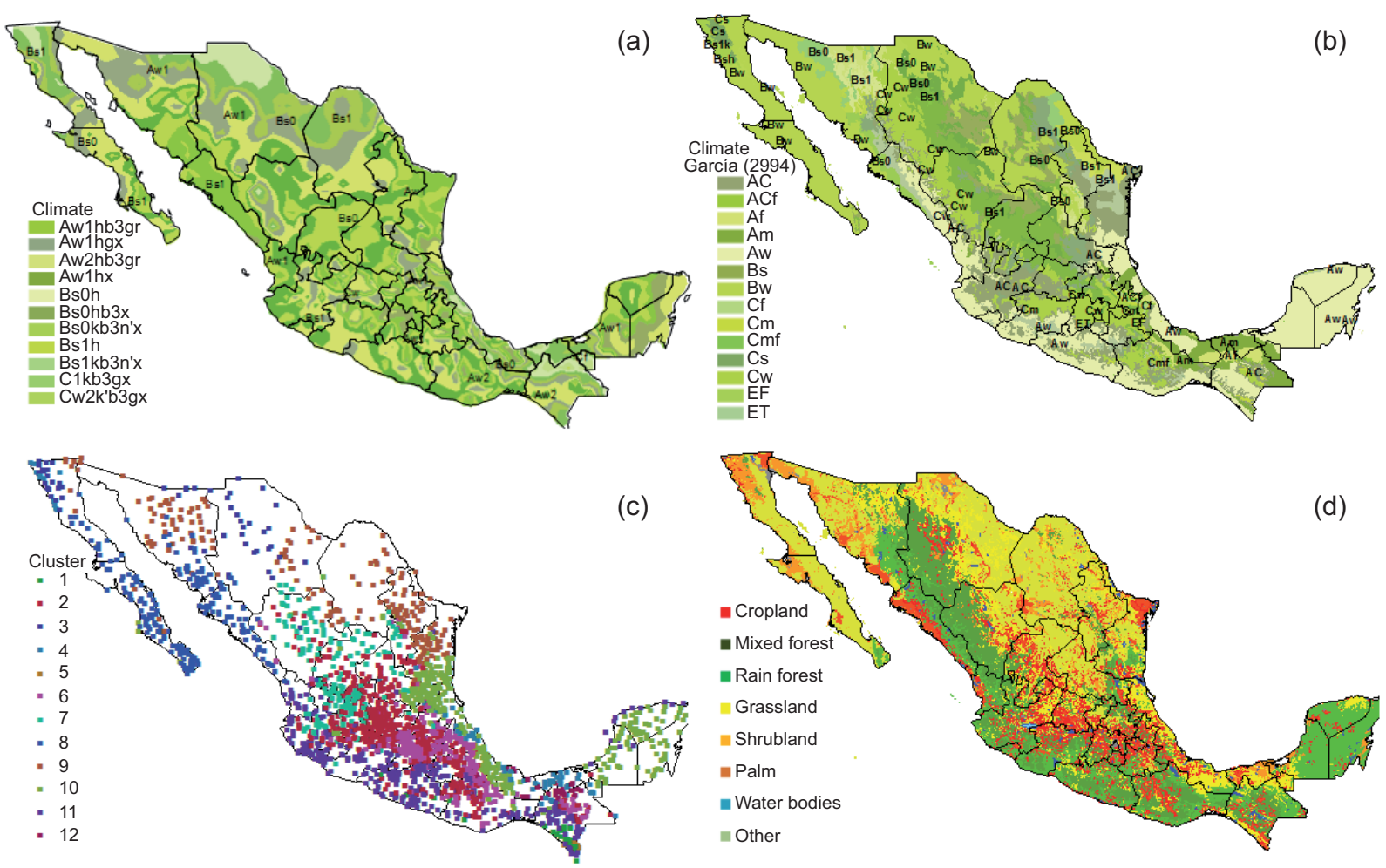

Fig. 4. (a) Climate regionalization types correspond to clustered regions; (b) Climate classification of Köppen modified by García (2004); (c) Stations grouped by cluster number; (d) Major vegetation groups in Mexico. 
ophies. While García (2004) includes geographic and topographic assessment criteria for boundary assignment, we base spatial boundary assignments on geostatistical techniques.

Figure $4 \mathrm{~d}$ shows the cover vegetation; it is observed a pattern width of dominant crops in climates Bs and Aw, principally where rain-fed crops are established. Historically crops were established in rangelands of dominant grasslands landscapes.

Arid and semi-arid climates (type) B cover most of the Mexican territory from the northwest in the peninsula of Baja California, and especially in the central-north region. This region is defined by a geographic effect. The differences in altitude between the center highlands and the coastal plains result in a large climate mosaic and vegetation gradient. Furthermore, the arrangement of mountains directly influences the distribution of moisture and temperature ranges. These factors partially define the aridity of that region known as the Altiplano. The large proportion of continental land in the north part of Mexico is characterized by arid regions that limit areas of scrubland and grassland. Therefore, grasslands are widely distributed in these climatic regions, with precipitation conditions as the main driver, expressed in different representative species of grassland within each region. For example, semiarid grasslands of the Chihuahuan Desert can be distinguished in the semi-dry and cold climate BS0 and Bs1 groups.

The northwestern part of Mexico is significantly affected by a high-pressure cell for most of the year increasing the degree of aridity (Mosiño and García, 1973). Additionally, this region is directly influenced by a cold Pacific Ocean current that has a noticeable effect on the climate of the Baja California peninsula and of the state of Sonora, which drives the vegetation of this region, marked by the dominance of arid spiny shrubland distinctive of Bs0 climates. Shrublands are almost uniformly distributed throughout almost all of the climatic regions due to the large number of species and groups of shrubs found in Mexico. Nevertheless, it is possible to make a sub-classification of types of shrubland in correlation with the climatic classification in a gradient of moisture, from semi-desert scrubs in regions with annual average rainfall of $300 \mathrm{~mm}$, to xeric scrub in regions with precipitation of $500-650 \mathrm{~mm}$.

\section{Conclusions}

By applying techniques that include a combination of PCA and HCA, it was possible to carry out a fast clustering method based on the number of the principal climate regions of Mexico; it allowed determining the maximum clusters number. By using the first three PC in the clustering method, the classification presented by multivariate techniques give a very close representation of previous regionalization work of García (2004).

The inclusion of the silhouette coefficient as a criterion to evaluate the clustering was very useful not only for grouping but also for determining the number of clusters. Therefore it was possible to determine a maximum number of clusters for hierarchical agglomerative clustering algorithms. The Ward algorithm gives a better grouping using the silhouette coefficient as a criterion. In agglomerative clustering algorithms it is important to obtain an adequate number of clusters, which can be evaluated by means of the silhouette coefficient. Our results show mostly positive values for this coefficient, which tells us that the grouping criteria are adequate. Ward's method is advantageous since it creates more homogeneous clusters from a covariance or correlation matrix.

This paper presents the results based on the correlation matrix, which delivered groups according to their variability. The importance of this regionalization for Mexico is that it provides the basis for further analysis on regional climate variations, according to their vulnerability to climate change. The statistical techniques applied to the climatic database to generate a climate map show a high correspondence with the land cover map. By disaggregating station in groups, we can infer, in terms of the dominant vegetation, which of these regions will be more susceptible in its climatic structure under global climate variations.

\section{Acknowledgments}

This work was supported by the project SEP-CONACYT CB-2011-01- 168011. We thank Dr. Juan Gaviño Rodríguez for his comments on this manuscript.

\section{References}

Bonan G.B., S. Levis, S. Sitch, M. Vertenstein and K.W. Oleson, 2003. A dynamic global vegetation model for use with climate models: concepts and description of 
simulated vegetation dynamics. Glob. Chang. Biol. 9, 1543-1566. DOI: 10.1046/j.1365-2486.2003.00681.x Bravo Cabrera J.L., E. Azpra Romero, V. Zarraluqui Such, C. Gay García and F. Estrada Porrúa, 2012. Cluster analysis for validated climatology stations using precipitation in Mexico. Atmósfera 25, 339-354.

Brito-Castillo L., E.R. Vivoni, D.J. Gochis, A. Filonov, I. Tereshchenko and C. Monzón, 2010. An anomaly in the occurrence of the month of maximum precipitation distribution in northwest Mexico. J. Arid Environ. 74, 531-539. DOI: 10.1016/j.jaridenv.2009.10.014

Chapin III F.S., P.A. Matson and P. Vitousek, 2011. Principles of terrestrial ecosystem ecology. Springer Science \& Business Media, $455 \mathrm{pp}$.

Chen I.C., J.K. Hill, R. Ohlemüller, D.B. Roy and C.D. Thomas, 2011. Rapid range shifts of species associated with high levels of climate warming. Science 333, 1024-1026. DOI: 10.1126/science. 1206432

Comrie A.C. and E.C. Glenn, 1998. Principal components-based regionalization of precipitation regimes across the Southwest United States and Northern Mexico, with an application to monsoon precipitation variability. Clim. Res. 10, 201-215.

Cramer W.P. and R. Leemans, 1993. Assessing impacts of climate change on vegetation using climate classification systems. In: Vegetation dynamics \& global change (A.M. Solomon and H. Shugart, Eds.). Springer, 190-217 pp.

De Gaetano A.T., 1996. Delineation of mesoscale climate zones in the Northeastern United States using a novel approach to cluster analysis. J. Clim. 9, 1765-1782. DOI: 10.1175/1520-0442(1996)009<1765:DOMCZI >2.0. $\mathrm{CO} ; 2$

Elmore K.L. and M.B. Richman, 2001. Euclidean distance as a similarity metric for principal component analysis. Mon. Wea. Rev. 129, 540-549. DOI: 10.1175/1520-0493(2001)129<0540:EDAASM $>2.0$. $\mathrm{CO} ; 2$

Englehart P.J. and A.V. Douglas, 2002. Mexico's summer rainfall patterns. An analysis of regional modes and changes in their teleconnectivity. Atmósfera 15, 147-164.

Estrada F., A. Martínez-Arroyo, A. Fernández-Eguiarte, E. Luyando and C. Gay, 2009. Defining climate zones in Mexico City using multivariate analysis. Atmósfera 22, 175-193.

Farmer D., M. Sivapalan and C. Jothityangkoon, 2003. Climate, soil, and vegetation controls upon the variability of water balance in temperate and semiarid landscapes: Downward approach to water balance analysis. Water Resour. Res. 39, 1-21. DOI: 10.1029/2001WR000328

Fovell R.G. and M.Y.C. Fovell, 1993. Climate zones of the conterminous United States defined using cluster analysis. J. Clim. 6, 2103-2135. DOI: 10.1175/1520-0442(1993)006<2103:CZOTCU $>2.0$. $\mathrm{CO} ; 2$

García E., 2004. Modificaciones al sistema de clasificación climática de Köppen, 5a. ed. Instituto de Geografía, UNAM, 90 pp.

Giddings L., M. Soto, B.M. Rutherford and A. Maarouf, 2005. Standardized precipitation index zones for Mexico. Atmósfera 18, 33-56.

Gong X. and M.B. Richman, 1995. On the application of cluster analysis to growing season precipitation data in North America east of the Rockies. J. Clim. 8, 897-931. DOI: $10.1175 / 1520-0442(1995) 008<0897$ :OTAOC$\mathrm{A}>2.0 . \mathrm{CO} ; 2$

Kalkstein L.S., G. Tan and J.A. Skindlov, 1987. An evaluation of three clustering procedures for use in synoptic climatological classification. J. Clim. Appl. Meteorol. 26, 717-730.

DOI: $10.1175 / 1520-0450(1987) 026<0717$ :AEOTCP $>2.0 . \mathrm{CO} ; 2$

Karlsen S.R. and A. Elvebakk, 2003. A method using indicator plants to map locale climatic variation in the Kangerlussuaq/Scoresby Sund area, East Greenland. J. Biogeogr. 30, 1469-1491.

DOI: 10.1046/j.1365-2699.2003.00942.x

Kelly A.E. and M.L. Goulden, 2008. Rapid shifts in plant distribution with recent climate change. Proc. Natl. Acad. Sci. 105, 11823-11826. doi: 10.1073/pnas.0802891105

Miranda F. and E.H. Xolocotzi, 1963. Los tipos de vegetación de México y su clasificación. Colegio de Postgraduados, Secretaría de Agricultura y Recursos Hidráulicos, Mexico,148 pp.

Mosiño A. and E. García. 1973. The climate of Mexico. In: Climates of North America, World Survey of Climatology 11 (R.A. Bysan and F.K. Hare, eds.). Elsevier, Amsterdam, 345-404.

Neilson R.P., 1995. A Model for predicting continental-scale vegetation distribution and water balance. Ecol. Appl. 5, 362-385.

DOI: $10.2307 / 1942028$

Palacio-Prieto J.L., G. Bocco, A. Velázquez, J.F. Mas, F. Takaki-Takaki, A. Victoria and F. González-Medrano, 2000. La condición actual de los recursos forestales en 
México. Resultados del Inventario Forestal Nacional 2000. Investigaciones Geográficas 43, 183-203.

Pineda-Martínez L.F., N. Carbajal and E. Medina-Roldán, 2007. Regionalization and classification of bioclimatic zones applying principal components analysis (PCA) in the central-northeastern region of México. Atmósfera 20, 111-222.

Rzedowski J., 2006. Relaciones geográficas y posibles orígenes de la flora. La vegetación de México. Comisión Nacional para el Conocimiento y Uso de la Biodiversidad, Mexico. Available at: . http://www. biodiversidad.gob.mx/publicaciones/librosDig/pdf/ VegetacionMx_Cont.pdf.

Richman M.B., 1981. Obliquely rotated principal components. An improved meteorological map typing technique? J. Clim. Appl. Meteorol. 20, 1145-1159.
Seager R., M. Ting, I. Held, Y. Kushnir, J. Lu, G. Vecchi, H.-P. Huang, N. Harnik, A. Leetmaa, N.-C. Lau, C. Li, J. Velez and N. Naik, 2007. Model projections of an imminent transition to a more arid climate in southwestern North America. Science 316, 1181-1184. DOI: $10.1126 /$ science. 1139601

Tan P.-N., M. Steinbach and V. Kumar, 2005. Cluster analysis: Basic concepts and algorithms. In: Introduction to data mining (P. Tan et al., Eds.). Addison-Wesley, Boston, 487-568.

Zhu C. and D.P. Lettenmaier, 2007. Long-term climate and derived surface hydrology and energy flux data for Mexico: 1925-2004. J. Clim. 20, 1936-1946.

DOI: $10.1175 /$ JCLI4086.1 